\author{
PROF. DR. SYED IJLAL HAIDER RIZVI \\ MBBS, FCPS (Forensic Medicine) \\ Head of Forensic Medicine Department \\ Quaid-I-Azam Medical College \\ Bahawalpur
}

\section{DR. MUHAMMAD ASLAM}

DMJ, MCPS

Head of Forensic Medicine Department

Madina University, Faisalabad.

\section{DR. MUHAMMAD SANAULLAH, MBBS}

Dr. Khurram Sohail Raja, DMJ

Assistant Professor of Forensic Medicine

Punjab Medical College, Faisalabad.

\section{Dr. Humaira Arshad, DMJ}

Assistant Professor of Forensic Medicine

Punjab Medical College, Faisalabad.

\title{
Article Citation:
}

Rizvi SIH, Aslam M, Sanaullah M, Raja KS, Arshad H. Firearm wounds; study of morphology caused by rifled weapon. Professional Med J Mar 2010;17(1):68-72.

ABSTRACT... Objectives: To study the different changes occurring at cellular level in firearm injuries from near to distant shots. Study Design: A prospective Study. Place and Duration of Study: Khyber Teaching Hospital Peshawar and B.V Hospital Bahawalpur. Material \& Methods: Bodies presenting for autopsy within 12 hours after firearm injury were included. Wounds expressing maximum details were selected for study. Tissue samples were taken from wounds and preserved in 10\% formalin. Sections were taken and slides were stained with Harris Haemotoxylin. Olympus P-6 was used for photography and Nikon ( FE-2 body) for gross and microscopic photography. Results: The morphology at cellular level was variable according to the distance of fire. Marked distortion and streaming of nuclei was more pronounced and evident in close contact wounds. However changes were less pronounced with the increasing distance. Section of exit lesion reveled splitting between dermis and epithelium. Further in this study rifle fire fatalities were maximum $(53.33 \%)$ and distant shot fatalities were predominant $(73.33 \%$.). Conclusion: Microscopy can also be used as an additional tool to differentiate between entry and exit wounds and for estimating range of fire.

Key words: $\quad$ Fire arm injuries, Cellular Changes, Pakistan.

\section{INTRODUCTION}

In our society the gun is a constant threat to our safety, and indeed a common killer. Firearm is the weapon responsible for great number of deaths in our country and the number is going up day by day. As per data collected from the police department crimes branch, Punjab, Sind and Northwest Frontier Province, the total number of homicides caused by the firearms has increased by more than $100 \%$ in the last five years ${ }^{1}$. The weaponry pattern observed in persons dying of unnatural deaths presented for autopsy at the department of Forensic Medicine and Toxicology Khyber Medical College Peshawar and B.V.
Hospital Bahawalpur also show Firearms to be the major causative agent responsible for such deaths ${ }^{2}$.

In fact the number of homicides, criminal and justifiable committed, with firearms, exceeds the number 
of homicides committed by all other modalities of violence ${ }^{3}$.

In the year 1998, there were 30708 deaths from firearms in the United States. This makes firearm injuries one of the top ten causes of death in the United States ${ }^{4}$.

Firearm fatalities are also on an increase in the Kingdom of Saudi Arabia, most of the victims are the young males and handguns are mostly the weapons causing such fatalities ${ }^{5}$. There has been an increasing trend in the homicidal as well as suicidal use of the firearms in South Africa ${ }^{6}$. Firearms cause more than three deaths daily in Canada $^{7}$.

Gun shot fatalities comprise a large fraction of deaths that require a thorough medico-legal study. In unwitnessed shootings and in cases where conflicting testimony obscures the truth, medical evidence may be the only key to the correct answer ${ }^{8}$.

The interpretation of firearm injuries entirely depends upon the examination of the body and clothing of the victim $^{9}$. Visual examination of the clothing and tissue from gun shot wounds provides information pertaining to the range of discharge of firearms, ${ }^{10}$ as does the morphology of entry and exit wounds ${ }^{11}$. The information gained from the distribution of powder residue on skin and clothing, helps to determine the range and the direction of fire. The size of the area of powder tattooing depends on a number of factors like distance from muzzle to target, Barrel length, type of propellant and weapon used ${ }^{12,13}$.

Every Firearm injury case is an opportunity for research and to exploit this opportunity, the pathologist must be aware of Firearm changes, ammunition changes and developments ${ }^{14}$.

\section{MATERIAL AND METHODS}

A prospective study was conducted, on the dead bodies presenting for autopsy at the Department of Forensic Medicine and Toxicology Khyber Medical College Peshawar and BV hospital Bahawalpur. 75 cases of
Firearm fatalities caused by rifled firearms (including the long and short barrel), irrespective of age and sex with definite known circumstances of death were included in the study. Bodies undergoing Putrefaction and those presented for autopsy after twelve hours of death were excluded from the study. All the cases in which shotgun were the weapons, causing the death were also excluded from the study. In cases where there were multiple wounds either entry or exit, only one wound complex exhibiting maximum details was selected for study. Dermal morphology of the wounds was studied by the following methods.

1. Naked eye examination was done and the findings were documented

2. Tissue samples of the wound complex were excised and the tissues were preserved in $10 \%$ formalin according to the procedure described by Millines ${ }^{16}$.

Sections were taken on labeled slides and stained by using haematoxylin and eosin, using the Harris Heamatoxylin ${ }^{21}$

Photography was done to record both the gross and the microscopic findings with the help of Nikon (FE2 Body) using both the micro as well as the macro lenses. Olympus P6 was used to have the photomicrograph. Kodak color 200 film was used for the purpose.

\section{RESULTS}

Table-I. Showing the weapons of offence in the firearm fatalities by rifled firearms

\begin{tabular}{|l|c|c|}
\hline Pistols and short guns & 10 & $13.33 \%$ \\
\hline Rifles non automatic & 25 & $33.33 \%$ \\
\hline Automatic rifles & 40 & $53.33 \%$ \\
\hline Total & 75 & $100 \%$ \\
\hline
\end{tabular}




\begin{tabular}{|l|c|c|}
\hline \multicolumn{3}{|c|}{ Table-ll. Showing range of fire } \\
\hline Contact shots & 11 & $14.67 \%$ \\
\hline Intermediate range shots & 09 & $12 \%$ \\
\hline Distant shots & 55 & $73.33 \%$ \\
\hline Total & 75 & $100 \%$ \\
\hline
\end{tabular}

Table-III. Showing the number of lesions studied and their nature in firearm fatalities due to rifled firearm

\begin{tabular}{|l|c|c|}
\hline Entries lesions only & 10 lesions & \multirow{2}{*}{$\begin{array}{c}\text { Total entry } \\
75 \text { lesions }\end{array}$} \\
\cline { 1 - 2 } Entries with exit lesions & 65 lesions & \\
\hline Exit lesions & \multicolumn{2}{|c|}{65 lesions } \\
\hline Bullet recovery & \multicolumn{2}{|c|}{10 cases } \\
\hline
\end{tabular}

Microscopic examination, Histologic findings were grouped according to the type of the wounds i.e. Contact, intermediate range and distant range wounds and on the bases of being an entry or and exit lesion.

The results were as following:

In all the contact shots there was distortion and compression of the cells, with elongation and streaming of the nuclei. Nuclear swelling and vacuolization of the cells manifested as para-nuclear hallowing and was a consistent findings in all the sections observed in cases of the contact shots (Fig 1). There was total absence of epithelial elements in the area of defect/perforation made by the bullet. Dermal collagen showed a homogenized appearance and exhibited basophilia. Powder residues were observed at the edge of the lesion, as masses and clumps of black homogeneous material (Fig 2).

Sections of tissues made from the intermediate range shots revealed distortion and compression of the cells, with elongation and streaming of the nuclei. Nuclear swelling and vacuolization of the cells manifested as para-nuclear hallowing was a consistent findings in all the sections observed in these cases (Fig 3).
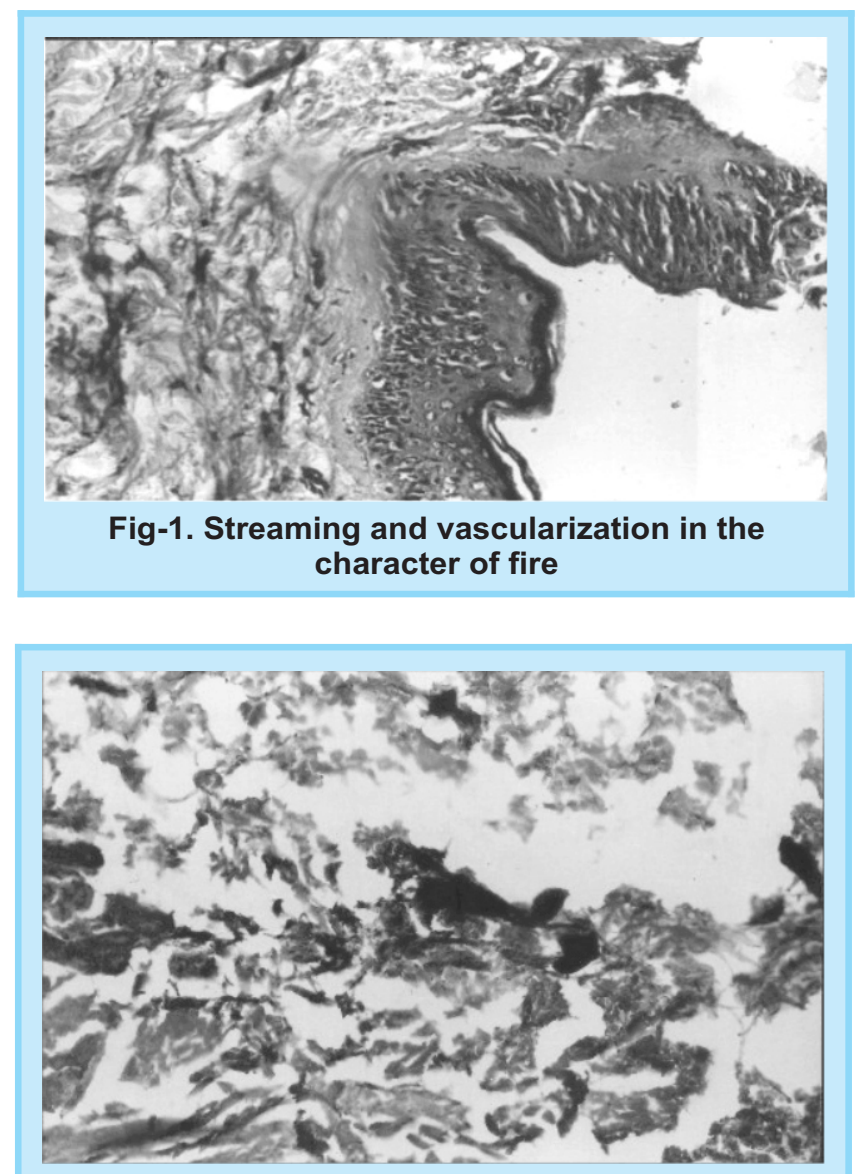

Fig-2.Gun Powder, Host Skin, Main Lesion

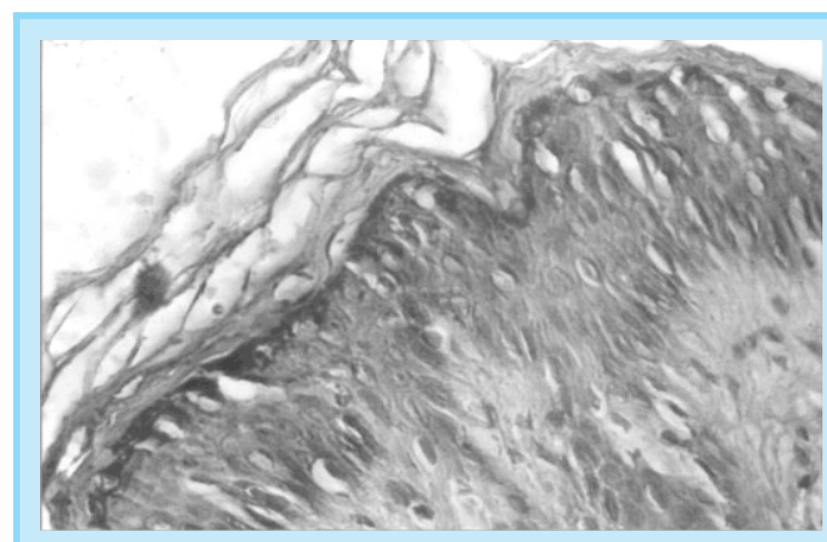

Fig-3.vascularization of the cells due to gas effects

There was total absence of epithelial elements in the 
area of defect/perforation made by the bullet. Dermal collagen showed a homogenized appearance and exhibited basophilia. The changes were similar in nature as observed in the contact lesions but the major difference was the pattern and density of the powder residue, which was abundant and distributed evenly throughout the lesion.

Sections prepared from the distant lesions exhibited elongation of the cells and nuclei, with streaming of the later. Vacuolization was a feature to be observed, but not well marked. Dermal changes showed lesser element of tinctorial changes (Fig 4). All the sections observed were devoid of the powder residue.

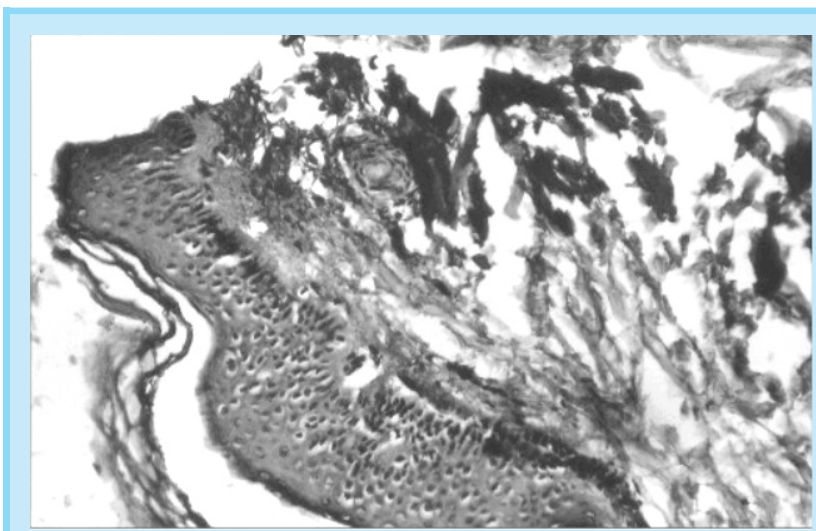

Fig-. Steaming of nuclei in the direction of force

The sections of the exit lesions showed obvious splitting between the dermis and the epithelium. Epithelium was markedly lifted. Lesser degree of changes as seen in the entry lesions but were qualitatively much lesser as compared to the entry lesions.

\section{DISCUSSION}

The microscopic evaluation of the section stained with haematoxylin and eosin revealed various cellular changes in the epithelium and in the dermis. The changes in the epithelium were distortion of the cells due to compression. Elongation of the nuclei with streaming and vacuolization of the deeper cells was observed which might be due to the heat effects or absorption of the energy transmitted through the moving projectile. The dermal changes were tinctorial in nature and there was basophilia to mention. The dermis was seen homogenized in most of the sections. These findings could be the result of hot projectile resulting into the coagulation necrosis. These changes were seen at all the ranges. There was presence of the powder residue at the margins of the lesion in contact shots. The intermediate lesions manifested abundance of powder residue in the sections. The epithelial changes were lesser in extent in the exit lesions, same was the case in dermis on examination. The reason for this change is due to the fact that bullet becomes colder before making an exit. The findings were similar to one made by, Fatteh ${ }^{15}$, Perper ${ }^{17}$ and Adelson ${ }^{19}$. The only difference in the present study and the one carried prior is the dermal findings, where only basophilia was observed. The reason for this difference may be because of the cases, which in the present study were mostly distant shots in nature.

\section{CONCLUSION}

These manifestations can also be used as tools for making an estimate regarding the range of fire. The direction of fire can also be made out on the basis of visual scrutiny of the wound complex. The entry and exit wounds, on observation, can also be differentiated, due to specific findings. Microscopy can also be used as and additional tool to differentiate between entry and exit wounds and also for estimating the range of fire.

\section{RECOMMENDATION}

Microscopy is of substantial help to resolve the issue of differentiating between entry and exit wounds caused by rifled fire arms when the findings are equivocal for both exit and the entries and is highly recommended to be undertaken.

\section{Copyright @ 16 April, 2009.}

\section{REFERENCES}

1. Data on record with the Police Department Government of Punjab, Sind and Northwest frontier Province.

2. Data of the Autopsies conducted in the Department Forensic Medicine and Toxicology, Khyber Medical College Peshawar during the year 2000. 
3. Ali MA, Ahmed R, Rahman AU. Involvement of manners and modalities in medico-legal deaths reported in the casualty Department Quaid-I-Azam Medical College Bahawalpur. The Professional 2000; 07:234-8.

4. Centers for Disease Control. Surveillance for fatal and nonfatal firearm related injuries: United States, 1993 1998. MMWR. 2000; 50:1-34.

5. Elfawal MA, Awad OA. Firearm fatalities in eastern Saudi Arabia:Impact of culture and legislation. American Journal of Forensic Medicine and Pathology. 1997; 4:391-6.

6. Larer LB, Matzopoulas RG, Phillips R. Violence and injury morality in the Cape Town metropolis. South African Medical Journal. 1997; 87:298-301.

7. Chapdelaine $A$, Maurice $P$. Firearm injury prevention and gun control in Canada. CMAJ 1996; 155:1285-9.

8. Adelson, L. Medical evidence in fatal gunshot injures. Am.J.clin.Pathol. 1953;23:758-67.

9. Stone 1C, Diamio VJM, Petty CS, Stone 1C. An experimental study of powder tattooing of the skin. J. Forensic.Sci.1978; 23:361-7.

10. Walker JT. Bullet holes and chemical residues in shooting cases. J.Grim.Law and Criminol.1940; 37:497521.

11. Adelson L. The pathology of Homicide. 1st ed. Illinois:Charles C. Thomas, 1974:188-318.

12. Moritz AR, Dutra FR. Scientific evidence in cases of injury by gunfire. Arch. Pahol. 1944; 37:340-50.
13. Dimaio VJM, Petty CS, Stone 1C. An experimental study of powder tattooing of the skin. J. Forensic. Sci. 1976; 21:367-372.

14. Petty CS. Firearm inures research: The role of practicing pathologist. Am.J.Clin Pathol. 1969; 52:277289.

15. Fatteh Abdullah: Medicolegal Investigations of Gunshot Wounds. 1st ed, Philadelphia:J.B. Lipponcott Company, 1976:82-126.

16. Makie RM Milne's Dermatopathology. 1st ed, London:Edward Arnold, 1984:4-44.

17. Perper JA, and Wecht $\mathrm{CH}$. Eds; Microscopic diagnosis in Forensic Pathology. 1st ed, Illinois:Charles C Thomas Springfield 1980. 327-336.

18. Curran WJ, McGarry LA, Petty. CS. Modern legal medicine, Psychiatry, and Forensic Sciences 1st ed, Philadelphia: F.A. Davis Company, 1980:415-471.

19. Adelson L. A microscopic study of dermal gunshot wounds. The American Journal of Clinical Pathology. 1961; 135:393-402.

20. Menzies RC, and Labowitz D.I. Characteristics of silenced firearms and their wounding effects. Journal of Forensic Sciences. 1981; 26:239-262.

21. Bancroft, JD, Stevens A. eds. Theory and practice of histological Techniques 3rd ed. Edinburgh:Churchill Living Stone, 1990:107-118.

\section{Objective stiruggle is joy and pleasure.}

Shuja Tahir 